$\overline{\text { ECONOMICS }}$

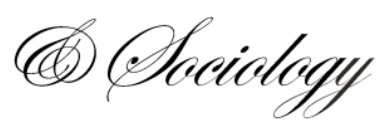

Nadirov, O., Dehning, B., \& Pavelkova, D. (2021). Taxes and the incentive to work under flat and progressive tax systems in Slovakia. Economics and Sociology, 14(2), 40-55. doi:10.14254/2071-789X.2021/14-2/2

\title{
TAXES AND THE INCENTIVE TO WORK UNDER FLAT AND PROGRESSIVE TAX SYSTEMS IN SLOVAKIA
}

\author{
Orkhan Nadirov \\ School of Public and International \\ Affairs, AD A University, \\ Baku, Azerbaijan \\ E-mail:onadirov@ada.edu.az \\ ORCID 0000-0003-0978-1387

\section{Bruce Dehning \\ Argyros School of Business and \\ Economics, Chapman University, \\ Orange, CA United States; \\ Faculty of Management and \\ Economics, Tomas Bata \\ University, Zlin, Czech Republic \\ E-mail:bdebning@,chapman.edu; \\ debning@utb.cz. \\ ORCID 0000-0002-2216-6867} \\ Drahomira Pavelkova
Faculty of Management and
Economics, Tomas Bata University
in Zlin,
Zlin, Crech Republic
E-mail:pavelkova@,utb.cz
ORCID 0000-0003-1399-6129
}

Received: June, 2020

1st Revision: December, 2020

Accepted: May, 2021

DOI: $10.14254 / 2071-$

789X.2021/14-2/2

JEL Classification: H24, $\mathrm{J} 22$.

\begin{abstract}
This study examines the impact of taxes on the incentive to work under flat and progressive tax systems. Of particular interest are the changes from progressiveto-flat and flat-to-progressive tax conditions. To measure the impact of taxes on the incentive to work under both scenarios, we relate hours worked with the effective marginal tax rates. Using national accounts data and the Prescott's (2004) labor market model, Slovakian work hours were examined at points in time around the adoption of a flat tax system in 2004 and a progressive tax system in 2013. In Slovakia, there was a transition from a progressive to a flat tax system in 2004, followed by a reversion back to a progressive tax system in 2013. Theoretically, the incentive to work increases when a progressive tax structure is replaced with a flat tax, while the incentive to work decreases in the opposite case. However, the findings show that when Slovakia replaced its progressive tax with a flat one, the actual hours worked decreased, contrary to predictions. When the flat tax was abandoned in favor of a progressive tax structure, hours worked also decreased, but less than when the flat tax was introduced, and significantly less than predicted by the model.
\end{abstract}

Keywords: flat tax system, progressive tax system, labor-leisure preferences, labor market model, Slovakia.

\section{Introduction}

In many developed countries there have been recent calls for a flatter tax structure, for example, in Italy and the United States (Daniel \& Martino, 2019; Lyman, 2019; Follain \& Lorenzo, 2019). Back in the 2016 election for the President in the United States, four of the 
Republican candidates proposed variations of a flat tax (Schoen, 2015). However, changing the tax structure assumes high costs, both due to implementation of the new rules by the government and then due to compliance of taxpayers. Therefore, such changes should not be made without the expectation that the benefits would outweigh the costs. There were several countries that adopted, and then abandoned, a flat tax structure, thus providing researchers with a natural experiment environment for testing the efforts of taxpayers under flat and progressive tax structures, helping us to infer the incentive or the disincentive effects of both. In this paper, we examine one such country, Slovakia, that adopted a flat tax in 2004 and switched back to a progressive tax structure in 2013.

Early theories of the flat tax system adoption were proposed by Hall and Rabushka $(1983,1985)$. However, such proportional (i.e., flat) tax systems were implemented in very few countries before the 1990s (Paulus \& Peichl, 2009; Adhikari \& Alm, 2016). After the collapse of the Soviet Union in 1991, flat taxes became a part of the transition economies in the Eastern and Central Europe (Easterbrook, 2008), and since 2009 thirty countries in the world adopted flat tax systems, with about half of them being in Eastern Europe (Paulus \& Peichl, 2009; Adhikari \& Alm, 2016). The adoption of a flat tax system was expected to boost the economies in these countries by influencing labor markets and increasing the gross domestic product (Peichl, 2014). However, in such countries as Iceland, Serbia, Ukraine, and Slovakia, the results were not as expected, and these countries abolished their flat tax systems in 2010, 2010, 2011, and 2013 respectively. Grabowski (2005) and Keen et al. (2008) have extensively reviewed the discussion of the flat tax reforms in Eastern Europe.

The current study attempts to test the relationship between taxes and the incentive to work in a natural experiment under two scenarios:

(i) Switching from a progressive tax system to a flat tax system.

(ii) Switching from a flat tax system to a progressive tax system.

\section{Optimal income taxation}

Selecting the proper tax system is a challenge for governmental tax administrators. One of the most significant concerns governments face is life cycle productivity shocks that cannot be privately insured by households, which subsequently affect their consumption level (Heathcote et al., 2017). There is a need for social insurance against these life cycle productivity shocks in the labor market, and progressive taxation is considered to be a useful tool against them (Heathcote et al., 2017). The impact of progressive taxation on life cycle productivity shocks can be explained by keeping a more equal income distribution and welfare among households. However, progressive taxation has distortionary effects on the incentive to work and saving decisions of households. The central claim in the literature is that the incentive to work increases in the case of a change from a progressive tax system to a flat tax system, due to the proportional feature of a flat tax system and low rates of taxation (Peichl, 2014). The rationale behind this idea is equity concerns and labor supply efficiency.

In the optimal taxation literature, Mirrlees (1971) is the seminal contribution to analyze the equity-efficiency trade-off. According to Mirrlees (1971), redistribution (i.e., equity concerns such as social benefits from equality) causes efficiency losses by causing labor-supply distortions through a labor-leisure and a consumption-saving decision and he proposes linearity of optimal taxation. On the other hand, Tuomala (1990) argues that the most efficient tax structure is non-linear, as redistribution can be achieved with less deadweight loss (i.e., less labor-supply and tax distortions) due to having more information on the earnings of households (Jacobs et al., 2010). Theoretically, the differences originate from which utility function is employed. Welfare gains can be achieved if the utilitarian planner makes a policy towards a flat 
$\operatorname{tax}$ (Conesa \& Krueger, 2006). The utilitarian social welfare function refers to the CobbDouglas preferences in consumption and leisure (Jacobs et al., 2010). However, employing a Rawlsian welfare function instead of a utilitarian function can favor progressive taxation, because it concentrates on households at the bottom of the distribution or features high inequality aversion by taking into account redistribution from high ability to low ability agents (Conesa \& Krueger, 2006).

\section{Laboratory experiments, simulation, and labor market models}

There are a few studies that employ laboratory experiments to test the effect of progressive tax systems on the incentive to work. For example, employing a real-effort task in a laboratory experiment, Sillamaa (1999) found that the incentive to work is higher under a flat tax system, and flattening the tax structure generated a significant increase in tax revenues. Similarly, Gamage et al. (2010) showed a considerably higher incentive to work in a flat tax system. However, Pa'ntya et al. (2016) found the opposite results, that the incentive to work increases when the change is from a flat tax system to a progressive tax system. Their findings support the real-effort experiments conducted by Fochmann and Weimann (2013), who showed the positive effect of direct and indirect progressive tax systems on the incentive to work. As shown, previous empirical findings are mixed on this topic. Moreover, the evidence from the experiments is not comparable because they do not hold total taxes and average tax rates constant. Despite having dissimilarities in the methodological approaches between this study and $\mathrm{Pa}$ 'ntya et al. (2016), it is interesting to test their idea with a real-world tax system in a country that actually adopted a flat tax system in 2004 and then switched back to a progressive tax system in 2013. We use the labor market model developed by Prescott (2004) to examine the aforementioned scenarios in Slovakia due to tax reforms in both scenarios.

The current study is consistent with two groups of studies demonstrating simulations of hypothetical flat taxes. The first set of studies of hypothetical flat tax systems correspond to simulation models that measure the potential effects of flat tax systems in Western countries that never adopted flat tax systems (e.g., Ventura, 1999; Aaberge et al., 2000; Caminada and Goudswaard, 2001; Fuest et al., 2008; Jacobs et al., 2010). On the other hand, Prescott's and Rogerson's studies refer to the labor market models that examine the effect of marginal tax rates on labor income in major advanced industrial countries (e.g., Prescott, 2004; Rogerson, 2006, 2007, 2008; Rogerson and Wallenius, 2009). Most studies on hypothetical flat tax reforms found that a flat tax system increases the incentive to work (Easterbrook, 2008; Paulus and Peichl, 2009). It is generally accepted that lower marginal tax rates increase the incentive to work due to the substitution from leisure to work (Prescott, 2004; Nadirov et al., 2017, 2020; Nadirov and Dehning, 2020), and higher taxes are perceived as a loss of individual freedom (Kirchler, 1997; Kirchler, 1999; Kirchler, 2007) by the extent to which individuals consider the power of, and trust in, tax authorities (Kirchler et al., 2008; Mas' ud et al., 2019). Dalton (2015) and Conesa and Kehoe (2017) also found a negative effect of taxes on aggregate hours worked per working-age person in Austria and Spain, respectively. This study differs from studies using simulation models by using actual changes between progressive and flat tax systems.

\section{Objective}

The current study contributes to the existing literature by addressing issues related to the effect of labor taxes on the incentive to work in real tax designs, including both flat and progressive tax systems. We relate hours worked in Slovakia with labor tax rates developed by Prescott (2004) and Mocan and Pogorelova (2015). In doing so, we obtain robust results for our 
predictions. Our findings imply that the incentive to work decreases in the case of a change from a flat tax system to a progressive tax system, but are inconclusive in the case of a change from a progressive tax system to a flat tax system. Overall, if decreases in the incentive to work can be attributed to the estimated effect of the flat-to-progressive condition, then the implementation of progressive tax systems in those countries should be re-evaluated from a labor market perspective by tax administrators and policymakers.

The remainder of the paper is organized as follows. In Section 1, the model is developed. In Section 2, we describe the methods used to estimate tax rates. Section 3 presents a comparison of the actual and predicted number of hours worked. Section 4 discusses the model predictions when holding the consumption-income ratio constant. Section 5 the goodness of fit, 6 the results, and section 7 analyzes the sensitivity of the results. Finally, in the last section, we conclude the paper.

\section{Labor market model}

The following labor market model is the one developed by Prescott (2004) to explain the tradeoff between work and leisure. He specified the utility of an infinitely-lived representative agent as

$$
\sum_{t=0}^{\infty} \quad \beta^{t}\left(\log \log c_{t}-\alpha \log \log \left(100-h_{t}\right)\right)
$$

Where $c_{t}$ shows consumption and $h_{t}$ represents weekly hours worked in the market in the time period $t$. The discount factor $\beta$ stands for the degree of patience, $0<\beta<1$, and $100-h_{t}$ measures non-market productive time (leisure). The $\alpha$ parameter is the positive constant that shows the value connected to leisure.

As this study is concerned with hours-worked in the year after tax reform, a singleperiod Prescott model developed by Easterbrook (2008) is used. As in Easterbrook (2008), the time period, $t$, is equal to zero, so the utility function is represented by

$u(c, h)=(\log \log c-\alpha \log \log (100-h))$

The individual is subject to a budget constraint

$\left(1+\tau_{c}\right) c \leq\left(1-\tau_{h}\right) w h+b$

Taxes on consumption and labor are denoted by $\tau_{c}$ and $\tau_{h}$ respectively. $w$ denotes the real wage rate and $b$ represents non-labor income. Utility maximization with regards to consumption and labor is depicted below

$$
\begin{aligned}
& u_{c}=\lambda\left(1+\tau_{c}\right) \\
& \text { And } \\
& u_{h}=-\lambda\left(1-\tau_{h}\right) w
\end{aligned}
$$

The ratio of equation (1.4) and (1.5) shows the marginal rate of substitution between leisure and consumption

$$
-\frac{u_{h}}{u_{c}}=\frac{\left(1-\tau_{h}\right) w}{1+\tau_{c}}
$$

The labor and consumption tax rates can be captured by the effective marginal tax rate on labor income. The combination of labor and consumption gives us

$$
-\frac{u_{h}}{u_{c}}=\frac{\left(1-\tau_{h}\right) w}{1+\tau_{c}}=(1-\tau) w
$$

In the aforementioned equation, the fraction of $\left(1-\tau_{h}\right) /\left(1+\tau_{c}\right)$ denotes the tax wedge (Ohanian, et al. 2008, OECD 2019). Setting $(1-\tau)=\left(1-\tau_{h}\right) /\left(1+\tau_{c}\right)$, the effective marginal tax rate $\tau$ can be shown as

$$
\tau=\frac{\tau_{h}+\tau_{c}}{1+\tau_{c}}
$$


To build the key equilibrium relation, first, a derivation of equation (1.2), and then the first-order condition of the utility-maximizer will be utilized

$$
\begin{aligned}
& -\frac{u_{h}}{u_{c}}=\frac{a c}{1-h} \\
& \text { and } \\
& \frac{a c}{1-h}=(1-\tau) w
\end{aligned}
$$

The aggregate output in a dynamic economy is a Cobb-Douglas production function, with capital cost share $\theta$, where $0<\theta<1$, and labor cost share $(1-\theta)$.

$$
y=A k^{\theta} h^{-\theta}
$$

where $\mathrm{k}$ is capital, and $\mathrm{h}$ is the labor supply. Based on equation (1.11), the marginal product of labor was calculated

$$
y=(1-\theta) A k^{\theta} h^{-\theta}=(1-\theta) \frac{y}{h}
$$

Using $(1-\theta) \frac{y}{h}$ instead of $w$ in the first-order condition, $h$ can be measured by

$$
h=\frac{1-\theta}{1-\theta+\frac{c \alpha}{y 1-\tau}}
$$

Equation (1.13) is the key equilibrium to test the effect of flat and progressive taxes on the incentive to work, controlling for the consumption-income ratio (c/y ratio).

\section{Estimating tax rates}

Consumption and labor tax rates presented in this paper are calculated based on two different methodologies. These two approaches, the Prescott (2004) approach and the Mocan and Pogorelova (2015) approach, are presented in the following two sections.

\subsection{Prescott approach}

As Silva (2008) provides, taxes in the model should be related to the consumption and labor taxes in the actual economies. The following estimation for Slovakia closely follows the methodology of Prescott. However, it should be noted that Prescott's method for estimating tax rates is based on Mendoza et al. (1994) but with some significant differences.

Prescott (2004) follows the Feenberg and Coutts (1993) estimate of the marginal tax rate on labor income. Feenberg and Coutts (1993) use a representative sample of tax records to show how much tax revenue increases if every worker had an increase in their labor income of 1\%. This is known as the Feenberg-Coutts parameter and is represented as $f$ in equation 2.1.

$$
\tau=\frac{\tau_{s S}+f * \bar{\tau}_{i n c}+\tau_{c}}{1+\tau_{c}}
$$

Where $\tau_{s s}$ shows the marginal social security tax rate, $\bar{\tau}_{\text {inc }}$ denotes the average income tax rate, and $\tau_{c}$ the consumption tax rate.

Setting the Feenberg-Coutts parameter, $f$, to 1.6, as per Prescott (2004), to reflect the fact that the marginal tax rate exceeds the average tax rate results in the marginal income tax rate as follows:

$$
\tau=\frac{\tau_{S S}+1.6 * \bar{\tau}_{i n c}+\tau_{c}}{1+\tau_{c}}
$$

Table 1 contains estimated tax rates using the Prescott approach, with data from the Eurostat database (2019a, 2019b, 2019c) in Slovakia for the period from 2000 to 2016. National Accounts data on tax aggregates, GDP and its main components, and general government expenditures are only available for Slovakia after 2000 to measure effective marginal tax rates in Slovakia, 


\subsection{Mocan and Pogorelova approach}

Mocan and Pogorelova (2015) estimated consumption and labor taxes based on the methodology of Prescott, but with McDaniel's (2014) social security tax rates, $\tau_{s s}$, and average tax rates on household income, $\bar{\tau}_{\text {inc }}$. Table 1 contains estimated tax rates using the Mocan and Pogorelova approach, with data from McDaniel (2014). McDaniel (2014) estimated tax rates for Slovakia from 2000 to 2015.

Table 1. Actual average hours worked and the effective marginal tax rate (in percent) in Slovakia 2000-2016

\begin{tabular}{lccc}
\hline Year & Actual Hours & Prescott & M\&P \\
\hline 2000 & 20.17 & 54.9 & 41.8 \\
\hline 2001 & 20.04 & 53.1 & 41.3 \\
\hline 2002 & 19.88 & 53.0 & 42.2 \\
\hline 2003 & 20.28 & 53.0 & 42.2 \\
\hline 2004 & 20.00 & 51.1 & 41.1 \\
\hline 2005 & 20.52 & 50.7 & 40.4 \\
\hline 2006 & 20.61 & 47.6 & 37.9 \\
\hline 2007 & 21.10 & 47.5 & 38.2 \\
\hline 2008 & 21.40 & 47.0 & 37.4 \\
\hline 2009 & 20.34 & 45.9 & 36.9 \\
\hline 2010 & 19.94 & 45.2 & 37.0 \\
\hline 2011 & 20.07 & 46.2 & 38.1 \\
\hline 2012 & 20.14 & 45.7 & 38.2 \\
\hline 2013 & 20.11 & 48.9 & 40.1 \\
\hline 2014 & 20.08 & 50.5 & 40.8 \\
\hline 2015 & 20.54 & 52.4 & 41.5 \\
\hline 2016 & 21.10 & 52.6 & -- \\
\hline
\end{tabular}

Source: Authors own elaboration to measure effective marginal tax rates using data from Eurostat (2019a, 2019b, 2019c) and McDaniel (2014). Actual hours data is from the ILOSTAT (2019) database.

\section{Actual and predicted hours worked}

Using the same approach as Prescott (2004), actual average hours worked per person in the population are constructed by multiplying mean weekly hours actually worked per employed person by the employment-to-population ratio (ILOSTAT 2019). According to ILOSTAT (2019), working-age people refers to all individuals who are older than 15 years. Equation (1.13) is used to forecast the number of hours worked. There are two main parameters that need to be specified in equation (1.13) that are taken from Prescott (2014), the capital share parameter $(\theta=0.3224)$ and the leisure parameter $(\alpha=1.54)$. Comparing actual hours worked to predicted hours will show whether the labor market model overestimates or underestimates the number of hours worked. As shown in Table 2, the predicted hours worked for Slovakia are below the actual hours worked by 0.29 to 2.40 hours. The labor market model utilized provides a better fit when compared to predictions from the Prescott (2004) and Hallam and Weber (2008) models. The average absolute errors in Table 2 range from 0.29 to 2.40 hours, while in Prescott (2004) the average absolute errors are -1.9 to 9.1 hours and in Hallam and Weber (2008) the average absolute errors are 4.1 to 6.1 hours. As shown in Table 2, predicted hours worked and actual hours worked move in the opposite direction between 2003 and 2004 and in the same direction between 2012 and 2013. Switching from a progressive tax system to a flat 
tax system (between 2003 and 2004), the Slovakian tax rate decreased from 53.0\% to 51.1\%, leading to an increase in predicted hours worked from 17.88 to 18.76 . However, there was a decrease in actual hours worked from 20.28 to 20.00. Switching from flat tax rates to progressive tax rates (from 2012 to 2013), tax rates increased from 45.7 percent to 48.9 percent, leading to a decline in predicted hours worked from 19.85 to 18.90. Actual hours worked also decreased slightly, from 20.14 to 20.11 .

Table 2. Actual and predicted labor supply for Slovakia

\begin{tabular}{|c|c|c|c|c|c|c|c|}
\hline \multirow[b]{2}{*}{ Year $^{2}$} & \multirow[b]{2}{*}{$\begin{array}{l}\text { Actual } \\
\text { (hours) }\end{array}$} & \multicolumn{3}{|c|}{ Prescott ${ }^{1}$} & \multicolumn{3}{|c|}{ M\&P } \\
\hline & & $\begin{array}{l}\text { Tax } \\
\text { Rate } \\
(\tau) \\
\end{array}$ & $\begin{array}{c}\begin{array}{c}\text { Predicted } \\
\text { (hours) } \\
(h)\end{array} \\
\end{array}$ & $\begin{array}{c}\text { Error } \\
\text { (hours) }\end{array}$ & $\begin{array}{l}\text { Tax } \\
\text { Rate } \\
(\tau)\end{array}$ & $\begin{array}{c}\text { Predicted } \\
\text { (hours) } \\
(h)\end{array}$ & $\begin{array}{c}\text { Error } \\
\text { (hours) }\end{array}$ \\
\hline 2003 & 20.28 & 53.0 & 17.88 & 2.40 & 42.2 & 21.11 & 0.83 \\
\hline 2004 & 20.00 & 51.1 & 18.76 & 1.24 & 41.1 & 21.75 & 1.75 \\
\hline 2012 & 20.14 & 45.7 & 19.85 & 0.29 & 38.2 & 21.98 & 1.84 \\
\hline 2013 & 20.11 & 48.9 & 18.90 & 1.21 & 40.1 & 21.45 & 1.34 \\
\hline
\end{tabular}

1 "Prescott" indicates the Prescott approach; "M\&P" indicates the Mocan and Pogorelova approach.

2003 Year Prior to Flat Tax; 2004 1st Year of Flat Tax; 2012 Year Prior to Progressive Tax; 2013 1st Year of Progressive Tax

Source: Authors own elaboration

As shown in Table 2, the prediction for hours worked using the Mocan and Pogorelova approach for Slovakia are above the actual hours worked by about 0.83 to 1.84 hours. The labor market model utilized again provides a better fit compared to the predictions made by Prescott (2004), and Hallam and Weber (2008). In Table 2, predicted hours worked and actual hours worked move in the opposite direction between 2003 and 2004 and in the same direction between 2012 and 2013. Switching from a progressive tax system to a flat tax system (from 2003 to 2004), the Slovakian tax rate decreased from 42.2 percent to 41.1 percent, leading to an increase in predicted hours worked from 21.11 to 21.75 , compared to a decrease in actual hours worked from 20.28 to 20.00. Switching from flat tax rates to progressive tax rates (from 2012 to 2013), tax rates increased from 38.2 percent to 40.1 percent, leading to a decline in predicted hours from 21.98 to 21.45 . As shown previously, actual hours worked also decreased slightly, from 20.14 to 20.11 .

\section{Consumption-Income ratio}

To isolate the effect of taxes on hours worked, Ljungqvist et al. (2006) hold the consumption-income ratio (c/y ratio) constant. In the current analysis, the same approach is followed. The c/y ratios are shown in Table 3. Using the effective marginal tax rates calculated using the Prescott approach, Table 3 compares the predicted hours worked for Slovakia, using the actual c/y ratio in each period and while holding the c/y ratio constant at the level of the preceding period. Switching from a progressive tax system to a flat tax system (from 2003 to 2004), predicted hours worked increased by $3.28 \%$ if the c/y ratio had not changed from 2003 to 2004. Switching from a flat tax system to a progressive tax system (between 2012 and 2013), predicted hours worked decreased by $5.20 \%$ if the c/y ratio had not changed from 2012 to 2013. 
Table 3. Decomposition of predicted hours worked

\begin{tabular}{|c|c|c|c|c|c|c|}
\hline \multirow[b]{2}{*}{ Year $^{2}$} & \multirow[b]{2}{*}{$\begin{array}{c}\text { Period of } \\
c / y \text { ratio }\end{array}$} & \multirow[b]{2}{*}{$c / y$ Ratio } & \multicolumn{2}{|c|}{ Prescott $^{1}$} & \multicolumn{2}{|c|}{ M\&P } \\
\hline & & & $\begin{array}{c}\text { Predicted } \\
\text { (hours) } \\
(\text { h })\end{array}$ & \% Change & $\begin{array}{c}\text { Predicted } \\
\text { (hours) } \\
(h)\end{array}$ & \% Change \\
\hline 2003 & $2003 \mathrm{c} / \mathrm{y}$ ratio & 0.95 & 17.88 & & 21.11 & \\
\hline 2004 & $2004 \mathrm{c} / \mathrm{y}$ ratio & 0.93 & 18.76 & 4.92 & 21.75 & 3.03 \\
\hline 2004 & $2003 \mathrm{c} / \mathrm{y}$ ratio & 0.95 & 18.47 & 3.28 & 21.43 & 1.53 \\
\hline 2012 & $2012 \mathrm{c} / \mathrm{y}$ ratio & 0.97 & 19.85 & & 21.98 & \\
\hline 2013 & $2013 \mathrm{c} / \mathrm{y}$ ratio & 0.97 & 18.90 & -4.79 & 21.45 & -2.41 \\
\hline 2013 & $2012 \mathrm{c} / \mathrm{y}$ ratio & 0.97 & 18.82 & -5.20 & 21.37 & -2.79 \\
\hline
\end{tabular}

1 "Prescott" indicates the Prescott approach; "M\&P" indicates the Mocan and Pogorelova approach.

2003 Year Prior to Flat Tax; 2004 1st Year of Flat Tax; 2012 Year Prior to Progressive Tax; 2013 1st Year of Progressive Tax

Source: Authors own elaboration

Using the effective marginal tax rates derived using the Mocan and Pogorelova approach, Table 3 shows the predicted hours worked for Slovakia, first using the actual c/y ratio for the period and then the c/y ratio at the level of the preceding period. The $\mathrm{c} / \mathrm{y}$ ratios are shown in Table 3. Switching from a progressive tax system to a flat tax system (between 2003 and 2004), predicted hours worked increased by $3.03 \%$, but they would have increased by $1.53 \%$ if the c/y ratio had been constant. Switching from a flat tax system to a progressive tax system (between 2012 and 2013), predicted hours worked decreased by $2.41 \%$, but they would have decreased by $2.79 \%$ if the c/y ratio had been constant.

\section{Goodness of fit}

Two criteria are used to assess the goodness of fit: (1) the difference between actual and predicted hours worked, and (2) the trend between actual and predicted hours worked. In Figure 1 , the solid line indicates the actual hours worked, and the dashed lines show the predicted hours worked based on the marginal tax rates on labor income calculated using the Prescott approach and the Mocan and Pogorelova approach. Also shown in Figure 1 are the two tax structure changes in Slovakia, the progressive-to-flat and flat-to-progressive tax conditions. These are indicated in Figure 1 by the blue and red vertical lines. Figure 1 shows that the model based on Prescott's approach to calculating tax rates underestimates the predicted labor supply for all years. The model based on tax rates calculated using the Mocan and Pogorelova approach overestimates the labor supply for all years except the year 2000. As shown in Figure 1, both actual and predicted hours worked were generally increasing from 2000 to 2008 . The decrease in hours worked that began in 2008 can be explained by the financial crisis that also began in 2008.

In the short run (e.g., the period from 2004 to 2005), the model predictions move in opposite directions, as the actual value moves up the predicted hours move down. We should note that individuals are responsive to the progressive-to-flat tax condition over the five years that incentive to work increased, as observed in the period 2004-2008. In the flat-to-progressive tax condition, while the model based on Prescott taxes shows almost the same trend in line with the actual values, the model based on Mocan and Pogorelova taxes shows only the one part of the story due to the missing value in 2016. The individuals are responsive to the flat-to- 
progressive tax condition in the short-run (e.g., the period from 2013 to 2014), as the model predictions move in the same line with the actual value. However, in the long run, the trend for actual and predicted hours, as observed in the period 2013-2016, is in the upward motion.

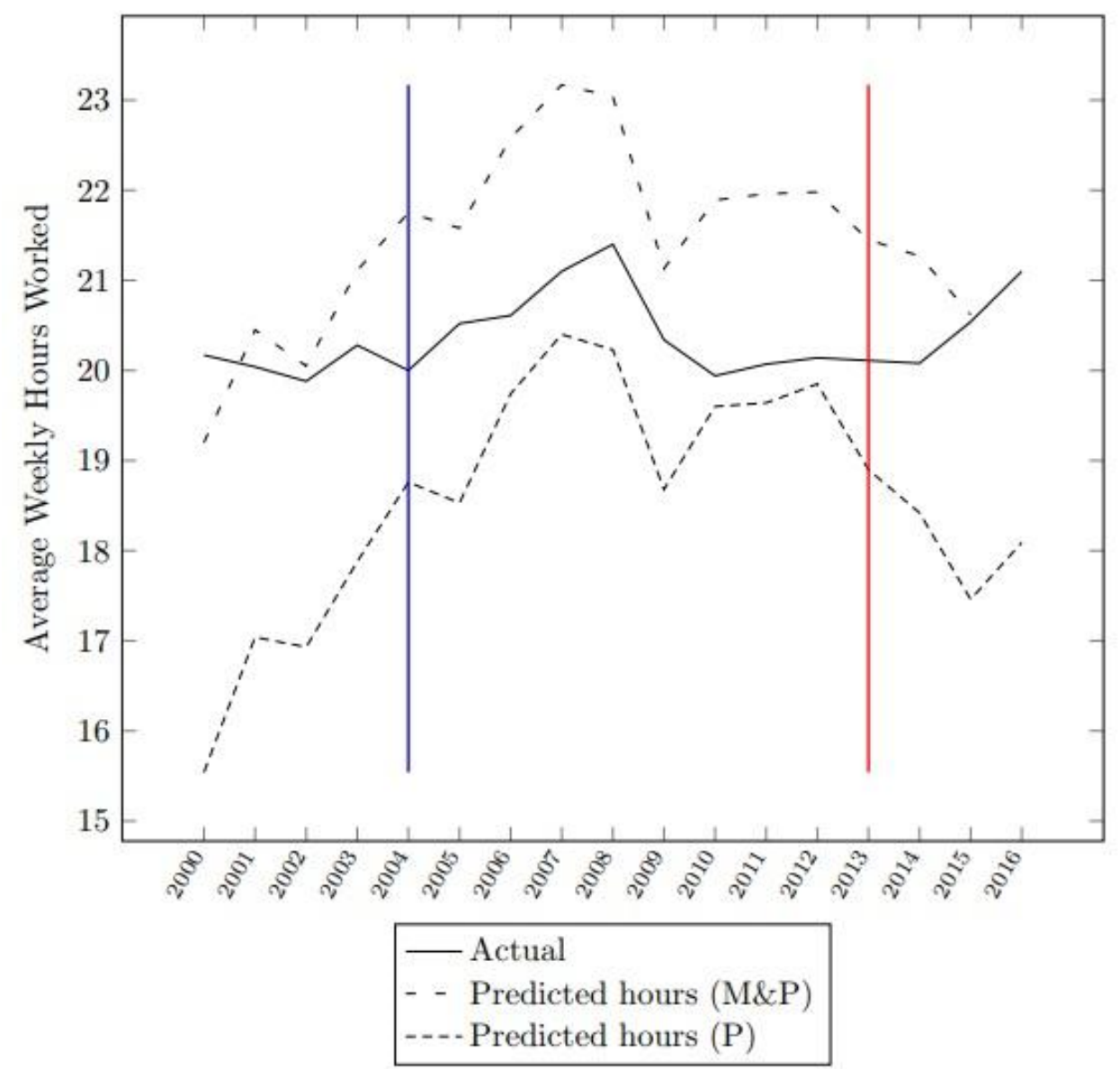

Figure 1. Labor Supply in Slovakia

Source: Authors' own elaboration.

\section{Results}

As shown previously in Table 2, the effective marginal tax rate on labor income decreased from 2003 to 2004 when Slovakia changed from a progressive to flat tax structure, and increased from 2012 to 2013 when Slovakia changed from a flat to a progressive tax structure. Holding everything else constant, this should have given workers the incentive to work more in 2004 and less in 2013. However, as shown in Table 4, when the tax structure in Slovakia changed from progressive tax rates to flat tax rates, actual hours worked decreased by 0.28 hours per week per working-aged person in the population. However, the predicted hours worked, holding everything constant except the change in the structure of the tax rates increased by 0.88 hours (Prescott approach) and 0.64 hours (Mocan and Pogorelova approach). Because the predicted hours worked accounts for the change in the effective marginal tax rate and holds the $c / y$ ratio constant, the difference between the actual and predicted tax rates can be attributed to the change in the structure of the tax rates. 
Table 4. Comparison of the change in actual and predicted hours worked

\begin{tabular}{cccc}
\hline Period & Actual hours & $\begin{array}{c}\Delta \text { Predicted } \\
\text { hours }(\mathbf{P})^{*}\end{array}$ & $\begin{array}{c}\Delta \text { Predicted } \\
\text { hours (M\&P)* }\end{array}$ \\
\hline $2003-2004$ & -0.28 & 0.88 & 0.64 \\
\hline $2012-2013$ & -0.03 & -0.95 & -0.53 \\
\hline
\end{tabular}

Source: Authors' own elaboration.

* (P) indicates the Prescott approach to estimating the effective marginal tax rate on labor income and (M\&P) indicates the Mocan and Pogorelova approach to estimating the effective marginal tax rate on labor income

\section{Sensitivity analysis}

Sensitivity analysis is performed by choosing different values for the parameters in the labor market model and then calculating predicted hours. Table 5 contains the output from the labor market model when alternative inputs are chosen for the key parameters. The benchmark model was based on the parameters of $\alpha=1.54, \theta=0.32$, and $f=1.6$. For choosing alternative values of $\theta$ and $f$, we refer to Silva (2008). Silva (2008) chose two different values for $\theta, 0.30$ and 0.35 , and two different values for $f, 1.4$ and 1.8. However, the value attached to leisure $(\alpha)$ is not related to any direct assumption. Following Silva (2008), the parameters are the same as previous research (Prescott, 2004). It should be noted that $\alpha$ it is one of the critical parameters in the labor market model because $\alpha$ it can have substantial differences between countries. However, the parameter $\alpha$ needs to be kept constant to isolate the changes in the incentive to work caused solely by taxes (Silva, 2008).

In the benchmark prediction, we followed Prescott (2004) and set $\alpha=1.54$. In addition to the benchmark prediction, two different values for $\alpha$ were tested, $\alpha=0.54$ and $\alpha=1.00$. Recall that the parameter $\alpha$ is positive, and aversion to work is positively correlated with $\alpha$. Increasing $\alpha$ increases the aversion to work, and lower values of $\alpha$ mean that individuals are less work averse.

In some cultures, the preference for leisure is considered high when the residents of that country engage less in labor activity (Glaeser et al., 2003; Blanchard, 2006; Alesina et al., 2005). However, it is hard to disentangle the effect of wages from the effect of taxes. Building their theories based on cultural attitude studies (Fernández et al., 2004; Fernández and Fogli, 2009; Fernández, 2011), recent scholarly literature finds the effect of culture of leisure on the labor supply by controlling per capita income (see Mocan and Pogorelova, 2015; Moriconi and Peri, 2019).

The predicted hours are closest to actual hours when $\alpha=1.54$, as in the benchmark model. For example, the predicted hours for Slovakia in 2003 slightly improve when we keep the parameters for $f=1.4$ and $\theta=0.3$ as the difference from the actual values is around 1.39 hours. A similar pattern is observed in 2004 when we keep the parameters for $f=1.4$ and $\theta=$ 0.3 as the difference is around 0.27 hours. For Slovakia in 2012, this difference is reduced to 0.11 hour when the parameters are set to $f=1.4$ and $\theta=0.32$. In 2013 , the difference is around 0.25 hours when we maintain the parameters for $f=1.4$ and $\theta=0.3$. To put it differently, predictions from the labor market model are more sensitive to the value attached to leisure $(\alpha)$ than the values of $\theta$ and $f$. Moreover, it should be noted that predictions from the labor market model are less sensitive to the values of $\theta$ and $f$, which is similar to the findings of Silva (2008). 
Table 5. Predictions from the labor market model when choosing different parameter values

\begin{tabular}{|c|c|c|c|c|c|c|c|c|c|c|}
\hline & & \multicolumn{9}{|c|}{ Predicted Hours } \\
\hline & & \multicolumn{9}{|c|}{$\alpha=0.54$} \\
\hline & & \multicolumn{3}{|c|}{$\theta=0.30$} & \multicolumn{3}{|c|}{$\theta=0.32$} & \multicolumn{3}{|c|}{$\theta=0.35$} \\
\hline Year & $\begin{array}{l}\text { Actual } \\
\text { Hours }\end{array}$ & $\mathrm{f}=1.4$ & $f=1.6$ & $f=1.8$ & $\mathrm{f}=1.4$ & $f=1.6$ & $f=1.8$ & $\mathrm{f}=1.4$ & $f=1.6$ & $f=1.8$ \\
\hline 2003 & 20.28 & 39.90 & 39.08 & 38.23 & 39.13 & 38.31 & 37.47 & 38.14 & 37.33 & 36.50 \\
\hline 2004 & 20.00 & 41.21 & 40.49 & 39.74 & 40.43 & 39.70 & 38.97 & 39.43 & 38.71 & 37.98 \\
\hline 2012 & 20.14 & 42.79 & 42.18 & 41.56 & 41.99 & 41.39 & 40.77 & 40.99 & 40.38 & 39.77 \\
\hline \multirow[t]{3}{*}{2013} & 20.11 & 41.41 & 40.71 & 40.00 & 40.62 & 39.93 & 39.22 & 39.62 & 38.94 & 38.23 \\
\hline & & \multicolumn{9}{|c|}{$\alpha=1.00$} \\
\hline & & \multicolumn{3}{|c|}{$\theta=0.30$} & \multicolumn{3}{|c|}{$\theta=0.32$} & \multicolumn{3}{|c|}{$\theta=0.35$} \\
\hline Year & $\begin{array}{l}\text { Actual } \\
\text { Hours }\end{array}$ & $\mathrm{f}=1.4$ & $f=1.6$ & $f=1.8$ & $\mathrm{f}=1.4$ & $f=1.6$ & $f=1.8$ & $\mathrm{f}=1.4$ & $f=1.6$ & $f=1.8$ \\
\hline 2003 & 20.28 & 26.39 & 25.73 & 25.05 & 25.77 & 25.11 & 24.44 & 24.98 & 24.34 & 23.68 \\
\hline 2004 & 20.00 & 27.46 & 26.87 & 26.26 & 26.82 & 26.23 & 25.64 & 26.01 & 25.43 & 24.85 \\
\hline 2012 & 20.14 & 28.77 & 28.26 & 27.75 & 28.11 & 27.61 & 27.10 & 27.27 & 26.78 & 26.29 \\
\hline \multirow[t]{3}{*}{2013} & 20.11 & 27.62 & 27.05 & 26.47 & 26.98 & 26.41 & 25.84 & 26.17 & 25.61 & 25.05 \\
\hline & & \multicolumn{9}{|c|}{$\alpha=1.54$} \\
\hline & & \multicolumn{3}{|c|}{$\theta=0.30$} & \multicolumn{3}{|c|}{$\theta=0.32$} & \multicolumn{3}{|c|}{$\theta=0.35$} \\
\hline Year & $\begin{array}{l}\text { Actual } \\
\text { Hours }\end{array}$ & $\mathrm{f}=1.4$ & $f=1.6$ & $\mathrm{f}=1.8$ & $\mathrm{f}=1.4$ & $f=1.6$ & $f=1.8$ & $\mathrm{f}=1.4$ & $f=1.6$ & $f=1.8$ \\
\hline 2003 & 20.28 & 18.89 & 18.36 & 17.83 & 18.39 & 17.88 & 13.36 & 17.78 & 17.28 & 16.77 \\
\hline 2004 & 20.00 & 19.73 & 19.26 & 18.78 & 19.28 & 18.76 & 18.34 & 18.58 & 18.13 & 17.68 \\
\hline 2012 & 20.14 & 20.78 & 20.37 & 19.96 & 20.25 & 19.85 & 19.44 & 19.58 & 19.19 & 18.80 \\
\hline 2013 & 20.11 & 19.86 & 19.41 & 18.95 & 19.35 & 18.90 & 18.45 & 18.71 & 18.27 & 17.83 \\
\hline
\end{tabular}

Source: Authors' own elaboration.

\section{Conclusion}

The present study builds on the significant findings of Prescott (2004) by predicting the effect of taxes on the incentive to work in flat and progressive tax systems for Slovakia. The results do not confirm the prior literature that demonstrates that progressive tax rates negatively affect the incentive to work. As shown previously in Table 4, actual hours worked declined when a flat tax was adopted, despite the theoretical predictions that the number of hours worked should increase. When Slovakia abandoned the flat tax and returned to a progressive tax structure, theoretically there should have been a dramatic decline in the number of hours worked. However, there was almost no change in the actual hours worked. These results suggest that, in the context of Slovakia, the incentive to work decreases more when the change is from a progressive tax system to a flat tax system. Therefore, it is not recommended to change the current tax policy in Slovakia as the progressive tax system has fewer labor-supply distortions. But this is not the entire story. In addition, as shown in Table 5, sensitivity analysis supplies a magnitude for the effects of the culture of leisure preferences on the incentive to work in Slovakia. Focusing on the values attached to leisure preferences, we take two different parameters $(\alpha)$ of leisure for predicting hours worked, respectively $\alpha=0.54$ (less work averse) and $\alpha=1.00$ (high work averse). We found that the labor supply decisions of the taxpayers depend mainly on not only from the degree of the progressivity of taxes, but also the utility that they get from leisure. Rather than responding immediately to taxes in flat and progressive tax systems, taxpayers may also take into consideration the utility of leisure and how much they 
value their free time. Using the World Values Survey (WVS) and the European Social Survey (ESS), recent scholarly works find that cultural values of leisure preferences are a significant factor in the employment rates of individuals of European countries (Moriconi and Peri, 2019) and labor supplied by women (Giavazzi et al., 2009).

Nevertheless, the present study has limitations. First, the Prescott model has been criticized by many scholars due to the omission of other significant institutional factors (Alesina et al., 2005; Ljungqvist and Sargent, 2008). Second, in happiness research, Oishi et al. (2012) found that, on average, residents living in countries with more progressive tax structures are happier than residents living in countries with less progressive tax structures. Moreover, Oishi et al. (2018) found that poor residents in the United States are happier because of the progressivity of taxation, as it is characterized by less income inequality. They claim that reversing the progressive tax system to less progressive taxation may increase income inequality and can decrease the happiness of the poor residents of the United States. Akay et al. (2012) found the same results for the residents of Germany. This view was also mentioned for the Slovakian economy by Lenartova (2003), that introducing a flat tax system in Slovakia can benefit wealthy taxpayers more than poor taxpayers. We do not test the effect of the flat tax structure on different income categories, as stratified hours worked data is not available for Slovakia during this time period. Because poor workers were exempt from taxes, the flat tax did not change their taxable income when compared to the progressive tax system. Our findings are an aggregate measure of the labor supply of a heterogeneous population. Therefore, they cannot be compared to the happiness research, as we do not classify the individuals as a poor or rich due to the limitations of the national accounts data. The current study could be improved by including omitted significant institutional demographic factors. However, even in the absence of the institutional and demographic factors, it was possible to disentangle and identify the impact of tax progressivity and the culture of leisure on the incentive to work. Findings were also presented that suggest the preferences for leisure is likely increasing substantially over time in Slovakia. If this assumption holds, then we can assume that regardless of whether taxes are progressive or flat, taxpayers will work less in Slovakia when the preference for leisure is stronger. Therefore, we can conclude that leisure preferences cannot be treated as a constant term, which is emphasized in previous economic models (Giavazzi et al., 2009, Guan et al., 2018), and these substantial changes in the preference for leisure can stem from the changes in the level of economic development. As Bozkurt and Yesilada (2017) stated, there is a close association between economic development and cultural values, including attitudes towards leisure. They provide that individuals of the late capitalism place more emphasis on leisure and self-expression values, and this raised the importance of the leisure-oriented consumer culture.

Despite the limitations of the current study, it offers significant implications for future tax policies. To build a more complete labor tax model, future directions should examine other factors that affect the incentive to work. An interesting view of predicting the effect of taxes on the incentive to work in flat and progressive tax systems is that an association between these two variables can be not only connected to economic measures, but also a culture of leisure (Mocan and Pogorelova, 2015; Moriconi and Peri, 2019). Therefore, the main challenge for policymakers of these countries lies not only in the design of fiscal policies (taxes and government spending), but also searching for the cultural insights of those policies, such as evaluating the effectiveness of these policies through the individual preferences for a workleisure trade-off in the country of origin. For instance, we suggest that future studies could focus on comparing the motivation to work between natives and immigrants in Slovakia in both tax systems and compare their preferences for leisure. These types of epidemiological approaches can explain the different leisure preferences between individuals from different countries of 
origin. As per Grenčíková and Španková (2016), the approximate data for measuring this trend in the labor market can be collected from health insurance companies.

\section{Acknowledgement}

This research received no specific grant from any funding agency in the public, commercial, or not-for-profit sectors.

\section{References}

Aaberge, R., Colombino, U., \& Strøm, S. (2000). Labor supply responses and welfare effects from replacing current tax rules by a flat tax: Empirical evidence from Italy, Norway and Sweden. Journal of Population Economics, 13(4), 595-621.

Adhikari, B., \& Alm, J. (2016). Evaluating the economic effects of flat tax reforms using synthetic control methods. Southern Economic Journal, 83(2), 437-463.

Akay, A., Bargain, O., Dolls, M., Neumann, D., Peichl, A., \& Siegloch, S. (2012). Happy taxpayers? Income taxation and well-being (SOEP Paper No. 526).

Alesina, A., Glaeser, E., \& Sacerdote, B. (2005). Work and leisure in the United States and Europe: why so different?. NBER macroeconomics annual, 20, 1-64.

Blanchard, O. (2006). Discussion of Do Taxes Explain European Employment? Indivisible Labor, Human Capital, Lotteries, and Savings, by Lars Ljungqvist and Thomas Sargent. NBER Macroeconomics Annual, ed. Daron Acemoglu, Kenneth Rogoff and Michael Woodford. Cambridge, Mass.: MIT Press, 225-232.

Bozkurt, V., \& Yeşilada, B. A. (2017). Has Capitalism Lost its Puritan Spirit? What do Recent WVS Data Say about Religiosity and Work Values?. Economics and Sociology.

Bunn D., and Martino D.D. (2019, June 12). Italy Can Pay for a Flat Tax. Tax Foundation. Retrieved from https://taxfoundation.org/italy-flat-tax/

Caminada, K., \& Goudswaard, K. (2001). 'Does a flat rate individual income tax reduce tax progressivity? A simulation for the Netherlands'. Public Finance and Management, 1(4), 471-499

Conesa, J. C. \& Kehoe, T. J. (2017). Productivity, taxes, and hours worked in Spain: 19702015, SERIEs, 8(3), 201-223.

Conesa, J. C., \& Krueger, D. (2006). On the optimal progressivity of the income tax code. Journal of Monetary Economics, 53(7), 1425-1450.

Dalton, J. T. (2015). The evolution of taxes and hours worked in Austria, 1970-2005, Macroeconomic Dynamics, 19(8), 1800-1815.

Easterbrook, Kathleen F. (2008). Flat Taxes and Labor Supply, Ph.D. thesis, Citeseer.

Eurostat (2019a). Main national accounts tax aggregates. [Online] Available at: http://appsso.eurostat.ec.europa.eu/nui/show.do?dataset=gov_10a_taxag\&lang=eng

Eurostat (2019b). GDP and main components (output, expenditure and income). [Online] Available at: http://appsso.eurostat.ec.europa.eu/nui/show.do?dataset=nama_10_gdp\&lang=en

Eurostat (2019c). General government expenditure by function (COFOG) [Online] Available at: http://appsso.eurostat.ec.europa.eu/nui/show.do?dataset=gov_10a_exp\&lang=en

Feenberg, D., \& Coutts, E. (1993). An introduction to the taxsim model, Journal of Policy Analysis and management 12(1): 189-194.

Fernández, R. (2011). Does culture matter? In Handbook of social economics (Vol. 1, pp. 481510). North-Holland. 
Fernandez, R. \& Fogli, A. (2009). Culture: An empirical investigation of beliefs, work, and fertility. American Economic Journal: Macroeconomics, 1(1), 146-77.

Fernández, R., Fogli, A., \& Olivetti, C. (2004). Mothers and sons: Preference formation and female labor force dynamics. The Quarterly Journal of Economics, 119(4), 1249-1299.

Fochmann, M., \& Weimann, J. (2013). The effects of tax salience and tax experience on individual work efforts in a framed field experiment. FinanzArchiv: Public Finance Analysis, 69(4), pp. 511-542.

Follain J., \& Lorenzo T. (2019, March 18). China Vows to Counter Trump's Tariff Threat Escalating Trade War. Bloomberg. Retrieved from https://www.bloomberg.com/news/articles/2019-03-18/italy-populists-new-bone-ofcontention-is-expanded-flat-tax

Fuest, C., Peichl, A., \& Schaefer, T. (2008). Is a flat tax reform feasible in a grown-up democracy of Western Europe? A simulation study for Germany. International Tax and Public Finance, 15(5), 620-636.

Gamage, D., Hayashi, A. T., \& Nakamura, B. K. (2010). Experimental evidence of tax framing effects on the work/leisure decision. Leisure Decision (June 24, 2010).

Glaeser, E. L., Sacerdote, B. I., \& Scheinkman, J. A. (2003). The social multiplier. Journal of the European Economic Association, 1(2-3), 345-353.

Giavazzi, F., Schiantarelli, F., \& Serafinelli, M. (2009). Culture, policies and labor market outcomes (No. w15417). National Bureau of Economic Research.

Grabowski M. H. (2005). Reforms of tax systems in transition countries. Transition Studies Review, 12(2), 293-312.

Grenčíková, A., \& Španková, J. (2016). Labour Migration Trends in the Slovak Republic, Economics and Sociology, Vol. 9, No 2, pp. 158-167. DOI: 10.14254/2071789X.2016/9-2/11

Guan, J. X., Li, Y., Ye, K., \& Zhuang, W. (2018). Leisure Preference and Corporate Tax Planning.

Hall, Robert Ernest, and Alvin Rabushka. (1983). Low tax, simple tax, flat tax, McGraw-Hill Companies.

Hall, Robert Ernest, and Alvin Rabushka. (1985). The flat tax. Stanford: Hoover Institution Press.

Hallam, A. and Weber, E. J. (2008). Labor Taxes and Hours Worked in Australia, Australian Journal of Labor Economics (AJLE) 11(2): 117-128.

Heathcote, J., Storesletten, K., \& Violante, G. L. (2017). Optimal tax progressivity: An analytical framework. The Quarterly Journal of Economics, 132(4), 1693-1754.

ILOSTAT (2019). Hours of work. [Online] Available at: http://www.ilo.org/ilostat/faces/oracle/webcenter/portalapp/pagehierarchy/Page3.jspx? MBI_ID=8

Jacobs, B., de Mooij, R. A., \& Folmer, K. (2010). Flat income taxation, redistribution and labour market performance. Applied Economics, 42(25), 3209-3220.

Keen, M, Yitae K., \& Ricardo V. (2008). The "flat tax(es)": principles and experience. International Tax and Public Finance, 15(6), 712-751.

Kirchler, E. (1997). The burden of new taxes: acceptance of taxes as a function of affectedness and egoistic versus altruistic orientation. The Journal of Socio-Economics, 26(4), 421437.

Kirchler, E. (1999). Reactance to taxation: Employers' attitudes towards taxes. The Journal of Socio-Economics, 28(2), 131-138.

Kirchler, E. (2007). The economic psychology of tax behaviour. Cambridge University Press. 
Kirchler, E., Hoelzl, E., \& Wahl, I. (2008). Enforced versus voluntary tax compliance: The "slippery slope" framework. Journal of Economic Psychology, 29(2), 210-225.

Lenartova, G. (2003). Prepared tax reform in the Slovak Republic according to the criteria of tax theory and practice. Ekonomický Časopis, 51(6), 664-687.

Ljungqvist, L., Sargent, T. J., Blanchard, O., \& Prescott, E. C. (2006). Do Taxes Explain European Employment? Indivisible Labor, Human Capital, Lotteries, and Savings / Comments. NBER Macroeconomics Annual 21: 181-24

Ljungqvist, L., \& Sargent, T. J. (2008). Taxes, benefits, and careers: Complete versus incomplete markets. Journal of Monetary Economics, 55(1), 98-125.

Lyman J. Eric, (2019, June 04). New Analysis: As Italy's plans for flat tax gain steam, economists say it might hurt more than help. XINHUANET. Retrieved from http://www.xinhuanet.com/english/2019-06/04/c_138114226.htm

Mas' ud, A., Abd Manaf, N. A., \& Saad, N. (2019). Trust and power as predictors of tax compliance: global evidence. Economics \& Sociology, 12(2), 192-204.

Mendoza, E. G., Razin, A., \& Tesar, L. L. (1994). Effective tax rates in macroeconomics: Crosscountry estimates of tax rates on factor incomes and consumption. Journal of Monetary Economics, 34(3), 297-323.

McDaniel, C. (2014). Average tax series data, updated December 2014. "More countries, fewer years" file.

Mirrlees, J. A. (1971). An exploration in the theory of optimum income taxation. The review of economic studies, 38(2), 175-208.

Mocan, N. H., \& Pogorelova, L. (2015). Why Work More? The Impact of Taxes, and Culture of Leisure on Labor Supply in Europe, Technical report, National Bureau of Economic Research.

Moriconi, S., \& Peri, G., 2019. Country-specific preferences and employment rates in Europe. European Economic Review.

Nadirov, O., \& Dehning, B. (2020). Tax Progressivity and Entrepreneurial Dynamics. Sustainability, 12(9), 3584.

Nadirov, O., Aliyev, K., \& Dehning, B. (2017). To work more or less? The impact of taxes and life satisfaction on the motivation to work in continental and eastern Europe. Economics and Sociology, 10(3), 266-280.

Nadirov, O., Vychytilová, J., \& Dehning, B. (2020). Carbon Taxes and the Composition of New Passenger Car Sales in Europe. Energies, 13(18), 4631.

OECD (2019), Tax wedge (indicator). doi: 10.1787/cea9eba3-en (Accessed on 22 May 2019)

Ohanian, L., Raffo, A., \& Rogerson, R. (2008). Long-term changes in labor supply and taxes: Evidence from OECD countries, 1956-2004. Journal of Monetary Economics, 55(8), 1353-1362.

Oishi, S., Schimmack, U., \& Diener, E. (2012). Progressive taxation and the subjective wellbeing of nations. Psychological science, 23(1), 86-92.

Oishi, S., Kushlev, K., \& Schimmack, U. (2018). Progressive taxation, income inequality, and happiness. American Psychologist, 73(2), 157.

Pántya, J., Kovács, J., Kogler, C., \& Kirchler, E. (2016). Work performance and tax compliance in flat and progressive tax systems. Journal of Economic Psychology, 56, 262-273.

Paulus, A., \& Peichl A. (2009). Effects of flat tax reforms in Western Europe. Journal of Policy Modeling, 31(5), pp. 620-636.

Peichl, Andreas. (2014). Flat-rate tax systems and their effect on labor markets, IZA World of Labor.

Prescott, E. C. (2004). Why do Americans work so much more than Europeans? Technical report, National Bureau of Economic Research. 
Rogerson, R. (2006). Understanding differences in hours worked, Review of Economic dynamics 9(3): 365-409.

Rogerson, R. (2007). Taxation and market work: is Scandinavia an outlier? Economic theory 32(1): 59-85.

Rogerson, R. (2008). Structural transformation and the deterioration of European labor market outcomes, Journal of political Economy 116(2): 235-259.

Rogerson, R. \& Wallenius, J. (2009). Micro and macro elasticities in a life cycle model with taxes, Journal of Economic theory, 144(6), 2277-2292.

Schoen W. John, (2015, November 11). GOP 'simple' flat tax proposals simply don't add up. CNBC. Retrieved from https://www.cnbc.com/2015/11/11/gop-simple-flat-taxproposals-simply-do-not-add-up.html

Sillamaa, M. A. (1999). How work effort responds to wage taxation: A non-linear versus a linear tax experiment. Journal of Economic Behavior \& Organization, 39(2), 219-233.

Silva, A. C. (2008). Taxes and labor supply: Portugal, Europe, and the United States, Portuguese Economic Journal, 7(2), 101-124.

Tuomala, M. (1990). Optimal income tax and redistribution. OUP Catalogue.

Ventura, G. (1999). Flat tax reform: A quantitative exploration, Journal of Economic Dynamics and Control, 23(9-10), 1425-1458. 